\title{
CONF- $960723--5$
}

\section{ERNEST DRLANDI LAWRENCE BERKELEY NATIONAL LABDRATIRY}

\section{Predicting Ion Charge State Distributions of Vacuum Arc Plasmas}

\section{A. Anders and T. Schülke Accelerator and Fusion} Research Division

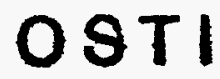

April 1996

To be presented at the

XVIIth International Symposium on Discharges and Electrical Insulation in Vacuum, Berkeley, CA, July 21-26, 1996, and to be published in the Proceedings 


\section{DISCLAIMER}

This document was prepared as an account of work sponsored by the United States Government. While this document is believed to contain correct information, neither the United States Government nor any agency thereof, nor The Regents of the University of California, nor any of their employees, makes any warranty, express or implied, or assumes any legal responsibility for the accuracy, completeness, or usefulness of any information, apparatus, product, or process disclosed, or represents that its use would not infringe privately owned rights. Reference herein to any specific commercial product, process, or service by its trade name, trademark, manufacturer, or otherwise, does not necessarily constitute or imply its endorsement, recommendation, or favoring by the United States Government or any agency thereof, or The Regents of the University of California. The views and opinions of authors expressed herein do not necessarily state or reflect those of the United States Government or any agency thereof, or The Regents of the University of California.

Ernest Orlando Lawrence Berkeley National Laboratory is an equal opportunity employer. 
XVIth International Symposium on

Discharges and Electrical Insulation in Vacuum (ISDEIV)

Berkeley, July 21-26, 1996

\title{
PREDICTING ION CHARGE STATE DISTRIBUTIONS OF VACUUM ARC PLASMAS
}

\author{
André Anders ${ }^{1}$ and Thomas Schülke ${ }^{2}$ \\ 1 Lawrence Berkeley National Laboratory, University of California, Berkeley, CA 94720 \\ 2 Fraunhofer Institute for Materials Physics and Surface Engineering (TWS), \\ Helmholtzstraße 20, 01069 Dresden, Germany
}

April 1996

This work was supported by the U.S. Department of Energy, Division of Advanced Energy Projects, under contract No. DE-AC03-76SF00098. 


\section{DISCLAIMER}

Portions of this document may be illegible in electronic image products. Images are produced from the best available original document. 


\title{
PREDICTING ION CHARGE STATE DISTRIBUTIONS OF VACUUM ARC. PLASMAS
}

\author{
André Anders ${ }^{1}$ and Thomas Schülke ${ }^{2}$ \\ ${ }^{1}$ Lawrence Berkeley National Laboratory, University of California, Berkeley, CA 94720 \\ ${ }^{2}$ Fraunhofer Institute for Materials Physics and Surface Engineering (IWS), \\ Helmholtzstraße 20, 01069 Dresden, Germany
}

\begin{abstract}
Multiply charged ions are present in vacuum arc plasmas. The ions are produced at cathode spots, and their charge state distributions (CSDs) depend on the cathode material but only little on the arc current or other parameters as long as the current is relatively low and the anode is not actively involved in the plasma production. There are experimental data of ion CSDs available in the literature for 50 different cathode materials. The CSDs can be calculated based on the assumption that thermodynamic equilibrium is valid in the vicinity of the cathode spot, and the equilibrium CSDs "freeze" at a certain distance from the cathode spot. (transition to a non-equilibrium plasma). Plasma temperatures and densities at the "freezing points" have been calculated, and, based on the existence of characteristic groups of elements in the Periodic Table, predictions of CSDs can be made for metallic elements which have not yet been used as cathode materials.
\end{abstract}

\section{INTRODUCTION}

The plasma of vacuum arcs is formed in small, quickly moving spots at the cathode surface (also called cathodic arcs in vacuum). In this paper we consider "low-current" vacuum arcs which have typically the following parameters: arc current 50-500 $A$, voltage drop between electrodes $20-25 \mathrm{~V}$, current density at cathode spots $10^{12} \mathrm{~A} / \mathrm{m}^{2}$, plasma density at the core of spots $10^{26} \mathrm{~m}^{-3}$ or greater, plasma velocity after acceleration $2 \times 10^{4} \mathrm{~m} / \mathrm{s}$. There is a wealth of literature describing the features of cathode spots of vacuum arcs, see for instance [1-3].

It has been known for many years that ions produced at cathode spots can be multiply charged. This has been extensively studied using time-of-flight charge-to-mass spectrometry, mainly motivated by the development of vacuum arc ion sources [4]. The most complete table of experimentally determined CSDs is given in Ref. [4] for 50 cathode materials.

The CSDs of vacuum arcs have a few remarkable features: They do not noticeably depend on the distance from the cathode and on the arc current (that's true in the current range of interest; we do not consider high-current arcs where the anode becomes actively involved in the plasma formation).

There have been only a few attempts to explain or simulate vacuum arc CSDs. An analysis of characteristic times has shown that local thermodynamic equilibrium (LTE) can be assumed in the vicinity of cathode spots [5] Ionizing and recombining collisions occur often during a characteristic expansion time as long as the plasma is very dense. The plasma composition (i.e., the ion CSD) can be calculated based on a set of Saha equations (see section 2). Far from the spot, ionizing/recombining collisions are sparse, and the plasma is in non-equilibrium with the consequence that CSDs remain constant (they are "frozen"). The transition region from equilibrium to non-equilibrium is critical for the establishment of the final, frozen CSD; the simplest assumption is that this transition occurs momentarily at a certain density and temperature. In a recent work [6] it was shown that this assumption works surprisingly well for lowcurrent vacuum arcs without magnetic field (it works less well at very high currents or in the presence of magnetic fields). In [6] calculations have been done to explain the CSDs of all 50 experimentally investigated cathode materials. It turned out that the CSD of cathode materials can be grouped using the Periodic Table of elements. Based on this knowledge, we predict CSDs for elements of the Periodic Table which have not yet been used as cathode materials or where no experimental data are available.

\section{Calculations of plasma COMPOSITIONS USING SAHA EQUATIONS}

Ionization and recombination reactions are balanced if the plasma is in local thermodynamic equilibrium (LTE). The balance equations reduce under LTE conditions to the Saha equations

$$
\begin{gathered}
\frac{n_{e} n_{Q+1}}{n_{Q}}=\Lambda_{B}^{-3} \frac{2 \Sigma_{Q+1}(T)}{\Sigma_{Q}(T)} \exp \left(-\frac{E_{Q}-\Delta E_{Q}}{k T}\right) \\
Q=0,1,2, \ldots Q_{\max }
\end{gathered}
$$

with 
where $n_{e}$ and $n_{Q}$ are the density of free electrons and ions of charge state $Q$, respectively, $Q=0$ for neutral atoms, $Q=1$ for singly ionized ions, etc., with $Q_{\max }$ the maximum charge state abundant in the plasma; $\Sigma_{Q}(T)$ is the temperature-dependent partition function of ions of charge state $Q, k$ is the Boltzmann constant, $T$ is the temperature,

$$
\Lambda_{B}=h /\left(2 \pi m_{e} k T\right)^{1 / 2}
$$

is the thermal De Broglie wavelength, and $E_{Q}$ is the ionization energy of the $Q$-fold charged ion. The partition function, $\Sigma_{Q}(T)$, reflects the electronic shell structure of atoms and ions and is tabulated for some elements in [7]. The lowering of the ionization energy, $\Delta E_{Q}$, reflects the particle interaction or nonideal nature of the plasma. The interaction becomes stronger at higher density At very high density, typically $n_{e} \geq 10^{26} \mathrm{~m}^{-3}$, the shifts of energy levels of bound electrons become very significant, and the lowering of the ionization energy can approach the value of the ionization energy itself (strongly nonideal plasmas).

The cathode spot plasma starts as a dense, nonideal plasma. Strong particle interaction keep the plasma in LTE, and its composition can be calculated if an appropriate model for $\Delta E_{Q}$ is used. Expansion leads to a less dense, less nonideal plasma, and eventually the collisions of the plasma particles become infrequent causing the plasma to depart from LTE. Ion CSDs can be calculated with Saha equations as long as LTE is valid, but complete balance equations (with ionization and recombination coefficients) have to be used under non-equilibrium conditions. At this point, a simplifying assumption has been made $[6,8]$ : once the plasma becomes "thin" so as to depart from LTE, the plasma composition calculated with Saha equations freezes, i.e. it is assumed that all changes in the plasma composition after transition to non-equilibrium are negligibly small. Observable CSDs (e.g. measured by time-of-flight charge-to-mass spectrometry) result from the freezing at the plasma density and temperature at the transition point from equilibrium to non-equilibrium; the plasma is at this point only weakly non-ideal which allows use of the relatively simple Debye-Hückel approximation [9] for the lowering of the ionization energy

$$
\Delta E_{Q}=\frac{(Q+1) e^{2}}{4 \pi \varepsilon_{o}\left(\lambda_{D}+\Lambda_{B} / 8\right)}
$$

where

is the Debye length, and $\varepsilon_{0}$ is the permittivity of vacuum. The system of equations (1)-(4) is completed by the quasi-neutrality condition

$$
n_{e}=\sum_{Q} Q n_{Q}
$$

\section{CALCULATION OF VACUUM ARC CHARGE STATE DISTRIBUTIONS}

In a recent publication [6] the Saha equations have been solved using tabulated ionization energies $[10,11]$. Values of plasma density and temperature have been found giving CSDs which fit best to the experimental results published by Brown [4]. The percentage of ion charge states are expressed as particle fractions of all ions,

$$
f_{Q}=\frac{n_{Q}}{\sum_{Q=1}^{\max } n_{Q}} \cdot 100 \%
$$

to allow comparison of experimental and best-fit data. Additionally, the amount of neutral atoms is given as

$$
f_{o}=\frac{n_{o}}{\sum_{Q=0}^{\max } n_{Q}} \cdot 100 \%
$$

that is the percentage of the total heavy particle density

$$
n_{h}=\sum_{Q=0}^{Q_{\max }} n_{Q}
$$

The mean ion charge is calculated by

$$
\bar{Q}=\sum_{Q=1}^{Q_{\max }} Q n_{Q} / \sum_{Q=1}^{Q_{\max }} n_{Q}
$$

All experimental vacuum arc ion CSD have been fitted, giving theoretical data for the plasma temperature and density at the freezing point for each cathode material [6]. 


\section{PREDICTION OF VACUUM ARC CSDs OF "NEW" ELEMENTS}

A major result of the calculations [6] is that the CSDs of elements can be grouped according to the Periodic Table of elements. This allows going one step further to calculate CSDs of elements which have up to now not been used as cathode materials (or whose CSDs have not yet been measured). Predictions cannot give precise percentages of onefold, twofold, threefold etc. ions but a good approximation of what can be expected when using these "new" materials. Plasma temperature and density at freezing have been determined by comparing the known data of elements of the same chemical and physical nature in the "neighborhood" of the Periodic Table. The cathode materials form the following 10 groups of elements

1) alkali metals (IA group): $\mathrm{Li}, \mathrm{Na}, \mathrm{K}, \mathrm{Rb}, \mathrm{Cs}, \mathrm{Fr}$;

2) alkaline earth metals (IIA group): $\mathrm{Be}, \mathrm{Mg}, \mathrm{Ca}, \mathrm{Sr}$, $\mathrm{Ba}, \mathrm{Ra}$;

3) transition metals of the IIIA-VIA group: $\mathrm{Al}, \mathrm{Ga}$, In, $\mathrm{Tl}, \mathrm{Sn}, \mathrm{Pb}, \mathrm{Sb}, \mathrm{Bi}, \mathrm{Po}$;

4) transition metals of the IIIB-VIIB group: Sc, Y, $\mathrm{Ti}, \mathrm{Zr}, \mathrm{V}, \mathrm{Cr}, \mathrm{Mn}$, including the ferromagnetic metals of the VIII group: $\mathrm{Fe}, \mathrm{Co}, \mathrm{Ni}$;

5) transition metals of the IIB group: $\mathrm{Zn}, \mathrm{Cd}, \mathrm{Hg}$

6) high conductivity metals (IB group): $\mathrm{Cu}, \mathrm{Ag}, \mathrm{Au}$, including the precious metals Pd and Pt of the VIII group;

7) refractory metals (IVB-VIIB and VIII group): $\mathrm{Nb}$, $\mathrm{Mo}, \mathrm{Tc}, \mathrm{Ru}, \mathrm{Rh}, \mathrm{Hf}, \mathrm{Ta}, \mathrm{W}, \mathrm{Re}, \mathrm{Os}$, Ir;

8) Lanthanides: La, Ce, Pr, Nd, Pm, Sm, Eu, Gd, $\mathrm{Tb}, \mathrm{Dy}, \mathrm{Ho}, \mathrm{Er}, \mathrm{Tm}, \mathrm{Yb}, \mathrm{Lu}$;

9) Actinides: Ac, Th, $\mathrm{Pa}, \mathrm{U}, \mathrm{Np}, \mathrm{Pu}, \mathrm{Am}, \ldots$;

10) semi-metal $C$ and semiconductors $S i$ and $G e$.

Table 1 shows the results for the 25 "new" elements, arranged in groups of related elements.

\section{DISCUSSION}

There are two major concerns of how reliable these calculations are. First, one has to to critically examine the validity of the general approach, i.e. the assumption of LTE for the dense spot plasma (validity of Saha equations in Debye-Hückel approximation) and instantaneous transtion to nonequilibrium at the "CSD freezing point". The second issue is the accuracy or error range one should expect for CSDs and "freezing point" data.

It has been shown in [6] that almost all experimental CSDs can be theoretically reproduced with surprisingly little deviations, with the exception of Mo, Ag, Hf, Ta, W, and Ir. Two explanations are considered for these elements: either the assumption of the instantaneous freezing is not a good approximation or the non-stationary nature of the cathode spot plasma production broadens the experimental CSD. Published data of CSD represent always values average over many individual discharges. It was found that the CSDs of individual discharges are different and therefore averaging causes CSD broadening [12]. The question to be addressed by future research is whether this kind of broadening is fully responsible for the observed discrepancy between theoretical and experimental CSD. If so, the calculations predict that the shot-to-shot variation of CSD is larger for the elements Mo, Ag, Hf, Ta, W, and Ir than for other elements. Due to the grouping on must expect that the experimental CSD of $\mathrm{Tc}, \mathrm{Ru}$, $\mathrm{Rh}, \mathrm{Re}$, and Os show a substatial broadending, too.

The question of accuracy of calculated CSDs and freezing point data must be answered very differently for the different groups of elements. There are groups of elements whose CSD is dominated by a specific charge state (for example 1+ for alkali metals (like $\mathrm{Na}$ ) and $2+$ for alkaline earth metals), almost regardless of what the parameters at freezing are. In these cases, the CSD is very reliably predicted (better than $3 \%$ ) but the parameters at freezing are not (these parameters are better estimated by either comparison with other elements or calculating freezing conditions using characteristic times and lengths). In contrast, there are many elements whose CSDs depend strongly on the plasma parameters at freezing (like $\mathrm{Ga}$ ) thus the parameters at the "CSD freezing point" can be relatively precisely determined by fitting the experimental CSD. Under these conditions, however, the CSDs of "new" elements have a relatively large uncertainty: the possible error of the ion percentages is estimated to be as great as a factor two. The behavior of the two types of elements is illustrated for $\mathrm{Na}$ and $\mathrm{Ga}$ (Fig. 1).

A final remark on the density of neutral atoms as given in Table 1. Neutral atoms appear in the Saha equations like any other charge state. The calculated density of neutral atoms is the result of ionization and recombination reaction under equilibrium conditions; it does not include the enhancement due to evaporating macroparticles and evaporation from hot, liquid metal pools of previously active craters. Therefore, neutral densities given in Table 1 represent a lower limit. While the ratios of ion charge states remain constant during plasma expansion, the neutral density can be enhanced due to these effects not considered in the model. 


\begin{tabular}{|c|c|c|c|c|c|c|c|c|c|c|c|c|}
\hline$Z$ & & $\begin{array}{c}n_{e, f r} \\
\left(m^{-3}\right)\end{array}$ & $\begin{array}{c}n_{f r} \\
\left(\mathrm{~m}^{-3}\right)\end{array}$ & $\begin{array}{l}T_{f r} \\
(\mathrm{eV})\end{array}$ & $\bar{Q}$ & $\begin{array}{c}0 \\
(\% \text { of } \\
\left.n_{f r}\right)\end{array}$ & $\begin{array}{c}1 \\
(\%)\end{array}$ & $\stackrel{2}{2}$ & $\begin{array}{c}3 \\
(\%)\end{array}$ & $\begin{array}{c}4 \\
(\%)\end{array}$ & $\begin{array}{c}5 \\
(\%)\end{array}$ & $\stackrel{6}{(\%)}$ \\
\hline \multicolumn{13}{|c|}{ "new" alkali metals (IA group) } \\
\hline 11 & $\mathbf{N a}$ & $1.0 \mathrm{e} 23$ & $1.0 \mathrm{e} 23$ & 1.8 & 1.00 & $2.2 e-2$ & 100.0 & $1.8 \mathrm{e}-5$ & & & & \\
\hline 19 & $\mathbf{K}$ & $1.0 \mathrm{e} 23$ & $1.0 \mathrm{e} 23$ & 1.7 & 1.00 & $1.7 e-2$ & 99.9 & $3.5 \mathrm{e}-2$ & $3.3 e-9$ & & & \\
\hline 37 & $\mathbf{R} \mathbf{b}$ & $1.0 \mathrm{e} 23$ & $1.0 \mathrm{e} 23$ & 1.6 & 1.00 & $2.0 \mathrm{e}-2$ & 99.9 & 0.15 & $9.7 e-8$ & & & \\
\hline 55 & $\mathrm{Cs}$ & $1.0 \mathrm{e} 23$ & $1.0 \mathrm{e} 23$ & 1.5 & 1.01 & $2.2 e-2$ & 99.2 & 0.70 & $1.8 \mathrm{e}-6$ & & & \\
\hline 87 & $\mathbf{F r}$ & $1.0 \mathrm{e} 23$ & $9.5 \mathrm{e} 22$ & 1.5 & 1.05 & $1.7 e-2$ & 94.5 & 5.5 & $2.2 \mathrm{e}-4$ & & & \\
\hline \multicolumn{13}{|c|}{ "new" alkaline earth metals (IIA group) } \\
\hline 4 & $\mathrm{Be}$ & $3.1 \mathrm{e} 24$ & $2.4 \mathrm{e} 24$ & 2.1 & 1.30 & 1.5 & 69.7 & 30.3 & & & & \\
\hline 88 & $\mathbf{R a}$ & $8.2 \mathrm{e} 23$ & $4.1 \mathrm{e} 23$ & 2.1 & 1.99 & $1.4 e-3$ & 1.5 & 98.1 & 0.4 & $1.1 \mathrm{e}-5$ & & \\
\hline \multicolumn{13}{|c|}{ "new" transition metals of the IIIA-VIA group } \\
\hline 31 & $\mathbf{G a}$ & $3.9 \mathrm{e} 24$ & $3.7 \mathrm{e} 24$ & 2.0 & 1.06 & 0.67 & 93.7 & 6.3 & $3.5 \mathrm{e}-3$ & & & \\
\hline 81 & TI & $7.5 \mathrm{e} 23$ & $4.7 \mathrm{e} 23$ & 2.3 & 1.60 & 0.28 & 41.6 & 56.8 & 1.6 & $5.0 \mathrm{e}-4$ & & \\
\hline 84 & $\mathbf{P o}$ & $1.7 \mathrm{e} 24$ & $1.4 \mathrm{e} 24$ & 1.8 & 1.20 & 1.55 & 79.8 & 20.2 & $9.3 e-3$ & & & \\
\hline \multicolumn{13}{|c|}{ "new" transition metals of the IIB group } \\
\hline 80 & $\mathbf{H g}$ & $6.0 \mathrm{e} 24$ & $4.7 \mathrm{e} 24$ & 2.3 & 1.32 & 2.7 & 68.5 & 31.5 & $2.4 \mathrm{e}-2$ & $1.6 \mathrm{e}-8$ & $\therefore$ & \\
\hline \multicolumn{13}{|c|}{ "new" refractory metals (IVB-VIIB and VII group) } \\
\hline 43 & Tc & $1.4 \mathrm{e} 25$ & $4.6 \mathrm{e} 24$ & 4.5 & 3.00 & $6.7 e-4$ & 0.35 & 19.6 & 60.0 & 19.9 & 0.13 & $8.1 e-6$ \\
\hline 44 & $\mathbf{R u}$ & $1.2 \mathrm{e} 25$ & $4.0 \mathrm{e} 24$ & 4.5 & 2.90 & $6.2 e-4$ & 0.36 & 16.9 & 74.9 & 7.8 & $1.3 \mathrm{e}-2$ & $2.2 e-7$ \\
\hline 45 & $\mathbf{R h}$ & $1.0 \mathrm{e} 25$ & $3.6 \mathrm{e} 24$ & 4.5 & 2.77 & $9.6 e-4$ & 0.64 & 25.3 & 70.4 & 3.6 & 2.8 & $1.4 \mathrm{e}-8$ \\
\hline 75 & $\mathrm{Re}$ & $1.8 \mathrm{e} 25$ & $5.8 \mathrm{e} 24$ & 4.3 & 3.05 & $1.4 \mathrm{e}-3$ & 0.44 & 15.0 & 63.7 & 20.7 & 0.16 & $1.6 \mathrm{e}-5$ \\
\hline 76 & Os & $1.6 \mathrm{e} 25$ & $5.3 \mathrm{e} 24$ & 4.3 & 2.95 & $2.2 e-3$ & 0.63 & 20.5 & 62.3 & 16.5 & $6.8 \mathrm{e}-2$ & $2.9 \mathrm{e}-6$ \\
\hline \multicolumn{13}{|c|}{ "new" lanthanides } \\
\hline 61 & $\mathbf{P m}$ & $1.2 \mathrm{e} 23$ & $5.5 \mathrm{e} 22$ & \begin{tabular}{|l|}
1.8 \\
\end{tabular} & 2.15 & $2.7 e-4$ & 0.87 & 82.8 & 16.3 & $2.4 \mathrm{e}-4$ & & \\
\hline 63 & Eu & $1.0 \mathrm{e} 23$ & $4.9 \mathrm{e} 22$ & 1.9 & 2.10 & $1.5 e-4$ & 0.65 & 88.9 & 10.5 & $2.7 e-4$ & & \\
\hline 65 & $\mathbf{T b}$ & $6.3 \mathrm{e} 23$ & $2.8 \mathrm{e} 23$ & 2.1 & 2.25 & $1.6 e-3$ & 1.7 & 71.5 & 26.8 & $5.3 e-3$ & & \\
\hline 71 & Lu & $1.0 \mathrm{e} 25$ & $5.1 \mathrm{e} 24$ & 2.4 & 2.00 & 0.11 & 17.7 & 64.1 & 18.1 & $6.6 e-4$ & & \\
\hline \multicolumn{13}{|c|}{ "new" actinides } \\
\hline 89 & Ac & $8.6 \mathrm{e} 23$ & $3.0 \mathrm{e} 23$ & 2.3 & 2.87 & $1.7 e-4$ & 0.27 & 12.4 & 87.3 & $1.7 e-2$ & $6.8 \mathrm{e}-9$ & \\
\hline 91 & $\mathbf{P a}$ & $1.0 \mathrm{e} 25$ & $3.3 \mathrm{e} 24$ & 3.0 & 3.14 & $1.2 e-3$ & 0.34 & 11.0 & 61.5 & 25.6 & $2.3 e-2$ & $8 \mathrm{e}-10$ \\
\hline 93 & $\mathbf{N p}$ & $8.9 \mathrm{e} 24$ & $3.0 \mathrm{e} 24$ & 3.0 & 2.93 & $1.6 e-3$ & 0.48 & 15.2 & 75.1 & 9.2 & $1.1 \mathrm{e}-3$ & $7 \mathrm{e}-11$ \\
\hline 94 & $\mathbf{P u}$ & $9.2 \mathrm{e} 24$ & $3.4 \mathrm{e} 24$ & 3.0 & 2.68 & $2.7 e-3$ & 0.82 & 31.0 & 67.6 & 0.54 & $4.1 \mathrm{e}-6$ & \\
\hline 95 & Am & $9.0 \mathrm{e} 24$ & $3.2 \mathrm{e} 24$ & 3.0 & 2.83 & $2.1 e-3$ & 0.66 & 18.5 & 77.8 & 3.0 & $6.0 \mathrm{e}-5$ & \\
\hline
\end{tabular}

Table 1: Predicted CSD of materials not yet used as vacuum arc cathodes. $Z$ : nuclear charge number; $n_{e, f r}, n_{f r}, T_{f r}$ : electron density, heavy particle density, and temperature at the freezing point of CSD; $\bar{Q}$ mean ion charge state; 0: percentage of atoms in plasma; $1,2,3,4,5,6$ : ion fractions. Notation: $2.4 \mathrm{e} 24=2.4 \times 10^{24}$. 


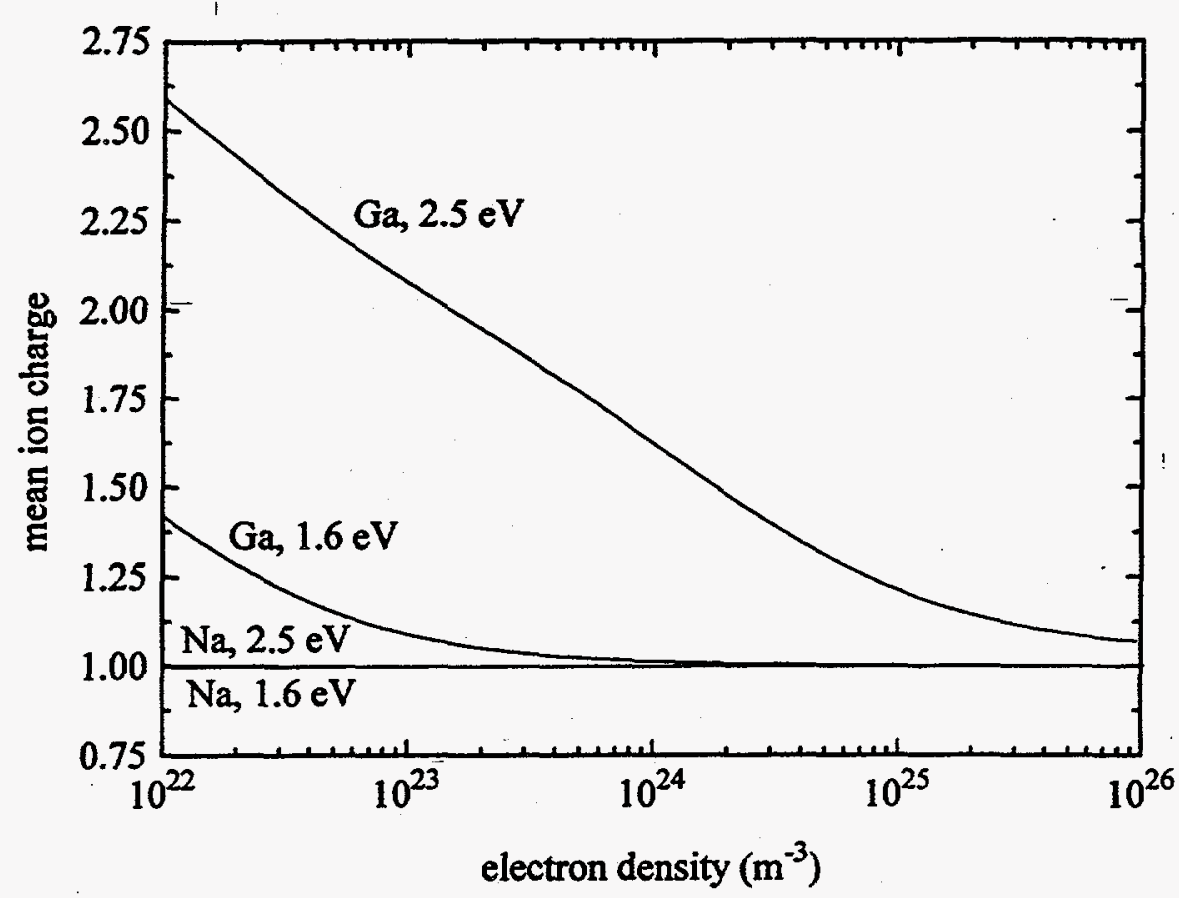

Figure 1: Mean ion charge as a function of density for gallium and sodium at two different plasma temperatures (Saha calculations). While the CSD of Na is dominated by $1+$ regardless of the plasma conditions, the CSD of $\mathrm{Ga}$ depends strongly on the plasma density, in particular at higher temperature.

\section{ACKNOWLEDGMENTS}

One of us (T. S.) was supported by a grant of the DAAD, Germany. This work was supported by the U.S. Department of Energy, Division of Advanced Energy Projects, under contract No. DEAC03-76SF00098.

\section{REFERENCES}

[1] G. A. Mesyats and D. I. Proskurovsky, Pulsed Electrical Discharge in Vacuum. Berlin: Springer-Verlag, 1989.

[2] Vacuum Arcs - Theory and Applications, ed. by J. M. Lafferty, New York: Wiley, 1980.

[3] Handbook of Vacuum Arc Science and Technology, ed. by R. L. Boxman, D. M. Sanders, and P. J. Martin, Park Ridge: Noyes Publications, 1995.

[4] I. G. Brown, Rev. Sci. Instrum. 65, 30613081, 1994.

[5] A. Anders, S. Anders, and E. Hantzsche, IEEE Trans. Plasma Sci. 17, 653-656, 1989.

[6] A. Anders, "Ion charge state distributions of vacuum arc plasmas - on the origin of species," submitted to Phys. Rev. E, 1996.
[7] H.-W. Drawin and P. Felenbok, Data for Plasmas in Local Thermodynamic Equilibrium. Paris: Gauthier-Villars, 1965.

[8] S. Anders and A. Anders, J. Phys. D: Appl. Phys. 21, 213-215, 1988.

[9] W. Ebeling, W.-D. Kremp, and D. Kraeft, Theory of Bound States and Ionization Equilibrium in Plasmas and Solids. Berlin: Akademie-Verlag, 1976.

[10] T. A. Carlson, C. W. Nestor, N. Wasserman, and J. D. McDowell, Atomic Data 2, 63-98, 1970.

[11] D. R. Lide and H. P. R. Frederikse, Handbook of Physics and Chemistry, 76 ed., Boca Raton, New York: CRC Press, 1995.

[12] A. Anders, S. Anders, B. Jüttner, and I. G. Brown, IEEE Trans. Plasma Sci. 21, 305-311, 1993. 